\title{
THE IMPACT OF SUPERVISOR-WORKER RELATIONSHIP ON WORKERS' SAFETY VIOLATIONS: A MODIFIED THEORY OF PLANNED BEHAVIOUR
}

\author{
Yikun SU®1, Weiyi $\mathrm{CONG}^{2}$, Huakang LIANG $\mathbb{B}^{3 *}$ \\ ${ }^{1}$ Shcool of Civil Engineering, Northeast Forestry University, Harbin 150040, China \\ ${ }^{2}$ School of Civil Engineering, Harbin Institute of Technology, Harbin 150090, China \\ ${ }^{3}$ School of Management, Harbin Institute of Technology, Harbin 150001, China
}

Received 03 February 2019; accepted 06 May 2019

\begin{abstract}
This study develops and tests an integrative model to better understand the mechanisms by which the leadermember exchange (LMX) determines workers' safety behaviours. The modified theory of planned behaviour (TPB) was proposed by using attitudinal ambivalence to replace univalent safety attitude. Empirical data were collected from 229 construction workers in China using a detailed questionnaire. Both situational and routine safety violations were considered in this model. The results showed that LMX had significant effects on both types of safety violations through three mediators from the modified TPB framework. Specifically, attitudinal ambivalence and group safety norm mediated the relationships between LMX and both types workers' safety violations. However, perceived behavioural control only mediated the relationship between LMX and individuals' routine safety violations. Furthermore, this research supported the distinctions between situational and routine safety violations. The indirect effects of LMX on individuals' situational safety violations took place mainly through group safety norm. By contrast, the indirect effects on individuals' routine safety violations took place mainly through attitudinal ambivalence and perceived behavioural control. Finally, the theoretical and practical implications, research limitations, and future directions were discussed. The results provide some meaningful insights into how to improve safety compliance behaviours from the perspective of supervisor-worker relationships.
\end{abstract}

Keywords: leader-member exchange, TPB, attitudinal ambivalence, situational safety violations, routine safety violations.

\section{Introduction}

The construction industry is one of the most hazardous industries in the world, which has witnessed high accident rate leading to huge losses of life and property (Choi, Ahn, \& Lee, 2017a; Fang \& Wu, 2013). Despite the increased efforts to reduce accidents, construction safety has not improved as much as other industries (Jiang, Fang, \& Zhang, 2015; Liang, Zhang, \& Su, 2018b; Shin, Lee, Park, Moon, \& Han, 2014). Previous studies have recognized that safety violations are one of the dominant causes of construction accidents (Fang, C. Wu, \& H. Wu, 2015; Fogarty, 2002). For instance, according to the statistics from the Health and Safety Executive (HSE), about $80-90 \%$ of all occupational incidents that occurred in the United Kingdom were derived from unsafe behaviours ( $\mathrm{Li}, \mathrm{Fan}, \& \mathrm{Wu}, 2018$ ). Blackmon and Raghu (1995) proposed that almost 98\% of the accidents were attributed in one way or another to unsafe behaviours. Therefore, it is pressuring to eliminate safety violations to further promote construction safety.
Previous studies have emphasized that the relationship between frontline supervisors and workers is one of the most important working relationships in the construction industry, and significantly impacts individual safety performance (Fang et al., 2015; Lingard, Cooke, \& Blismas, 2012). Construction workers rely heavily on their supervisors for allocating tasks and being guided and supported continuously because of the complex and dynamic nature of construction work. Thus, compared with the middle or top management, supervisors who interact with workers most frequently can directly contribute to the improvement of safety environment which determines workers' safety related perceptions and behaviours (Chih, Kiazad, Cheng, Lajom, \& Restubog, 2017; Zhang, Li, Fang, \& Wu, 2017). Furthermore, construction activities are characterized as decentralization and mobility, where frontline workers have more autonomy to make behaviour decisions discretionally, and change workplace frequently

*Corresponding author. E-mail: hkliang5493@hit.edu.cn 
(Choi et al., 2017a). These characteristics mean that compulsory norms fail to produce satisfactory effects on safety violations, while safety performance depends on, to some extent, the positive relationships between workers and their supervisors (Wu, Chong, Wang, \& Li, 2018). Although previous studies had examined the direct effects of supervisor-worker relationship on workers' safety-related behaviours (Kapp, 2012), they are still limited in interpreting the mediating mechanism underlying the above relationship.

Consistent with prior studies (Chih et al., 2017; Hofmann, Morgeson, \& Gerras, 2003), this study uses leader-member exchange (LMX) to capture the dynamic relationships between supervisors and their workers. LMX literature argued that supervisors form relationships of different quality, ranging from high to low, with their workers (Novak, Farr-Wharton, Brunetto, Shacklock, \& Brown, 2017). Specifically, a high-quality LMX relationship which is characterized by mutual respect, trust, and obligation, could predict workers' positive work performance (e.g., safety participation) (Lu, Weng, \& Lee, 2017). By contrast, low-quality LMX relationship that is lacking respect and trust, may lead to negative performance like safety violations (Novak et al., 2017). The conceptualization of LMX means that it can be used to understand the behavioural consequence of various forms of supervisor-worker relationship quality. Therefore, this research will explore how LMX, which measures supervisor-worker relationship quality, impacts workers' safety violations within the construction crew.

According to the Theory of Planned Behaviour (TPB), one of the most widely used psychological models explaining safety behaviours (Phipps, Beatty, \& Parker, 2015), personal attitude alongside subjective norms and perceived behavioural control are three determinants of intention engaging in behaviours (Ajzen, 1991). Accordingly, this paper aims to investigate the underlying mechanism through which supervisor-worker relationship influences workers' safety violations based on the framework of TPB. Traditional research regarding the TPB often included a univalent safety attitude which was predominantly divided into either positive or negative attitude. However, this univalent safety attitude is not consistent with the psychological conflicts when an individual violates safety rules on-site (Liang, Lin, Zhang, \& Su, 2018a). It's a universal phenomenon on the construction site when workers know safety violations are risky, but they cannot stop such behaviours because of production goal (Xu, Zou, \& Luo, 2018). According to review by Alper and Karsh (2009) on safety violations, violations are rarely committed with intentions for causing harms. Attitudinal ambivalence refers to the extent to which an individual simultaneously holds both positive and negative attitudes toward an object or behaviour, which could better capture above psychological characteristics during committing safety violations (Cacioppo, Gardner, \& Berntson, 1997). Prior research had proved the positive connection of attitudinal ambivalence to workers' safety violations (Cavazza \& Serpe, 2009). Accordingly, it's more explanatory to use a modified TPB framework where the safety attitude is replaced by attitudinal ambivalence toward safety compliance (AASC) to reveal the mediating role between LMX and safety violations.

According to previous research (Halbesleben, D. S. Wakefield, \& B. J. Wakefield, 2008; Liang, et al., 2018a), safety violations are categorized into routine and situational violations based on whether situational constraints are the main cause for violations. The situation when workers work around some safety procedures to achieve organizational benefits or personal gain is identified as routine violations (Hansez \& Chmiel, 2010). By contrast, situational safety violations are driven by situational constraints, where it is difficult for workers to comply with safety operation rules (Man, Chan, \& Wong, 2017). Previous studies had pointed out that situational and routine safety violations are distinct and are predicted by different factors (Chmiel, Laurent, \& Hansez, 2017; Hansez \& Chmiel, 2010). Accordingly, it is necessary to discriminate these two types of safety violations. In the following section, we will propose a hypothesized model about the effects of LMX on safety violations where the intermediate indicators are attitudinal ambivalence toward safety compliance (AASC), subjective norms (SN) and perceived behavioural control (PBC). The findings of this research will contribute to understanding the critical role of social interactions between supervisors and workers; and providing meaningful insights into the further prevention of safety violations on the construction site.

\section{Literature review}

In construction industry, supervisors are responsible for the operational management including planning, organizing and facilitating the daily task implementation, and giving relevant technical guidance and support for their crew member (Hardison, Behm, Hallowell, \& Fonooni, 2014; Lingard, Cooke, \& Blismas, 2011). Supervisors have the most frequent contacts with workers, and they are the directly responsible persons to guarantee good safety performance onsite (Hofmann et al., 2003; Kapp, 2012; Zohar, 2002). Therefore, compared with top managers and safety managers, workers' safety-related behaviours or performance are more likely to be influenced by their supervisors and their working relationships (Fang et al., 2015; Lingard et al., 2012). Despite the importance of supervisor-worker relationship for safety-related behaviours, it is still not adequately investigated in the construction area (Li et al., 2018). Consistent with previous research, this study uses the LMX to capture the dynamic relationships between supervisors and their workers. In addition, the underlying mechanism through which supervisor-worker's relationship influences workers' safety violations will be investigated based on a modified TPB framework. The hypothesized model will be developed in the following section.

\subsection{Leader-member exchange}

The positive role of supervisors' leadership in safety has been widely considered in previous studies (Michael, Guo, 
Wiedenbeck, \& Ray, 2006; Walumbwa, Cropanzano, \& Goldman, 2011). However, the research on relationship between supervisors and workers in the safety area is still lack (Mariani, Curcuruto, Matic, Sciacovelli, \& Toderi, 2017). Leader-Member Exchange (LMX) refers to the quality of supervisor-worker relationship and is considered to be a pivotal variable affecting employee's workrelated attitudes and behaviours (Detert \& Burris, 2007; Mariani et al., 2017; Nahrgang, Morgeson, \& Ilies, 2009; Walumbwa et al., 2011). This concept is coined from the social exchange theory which describes how workplace relationships affect organizational performance (Brandtmann, Scandura, \& Trillmich, 1999). The social exchange theory assumes that the mutual reciprocity develops over times if individuals experience positive interactions with their direct leaders or supervisors (Cropanzano \& Mitchell, 2005). The process involves supervisor's providing social supportive environment and concerning workers' well-beings, which then make workers committed to return high performance to the organization (Erdogan, Bauer, \& Taylor, 2015; Golden \& Veiga, 2018; Shore \& Wayne, 1993). LMX is one variable that captures the quality of such workplace relationship between supervisor and workers. Similarly, safety-specific LMX mainly focuses on the supervisor-worker interactions towards onsite safety (Michael et al., 2006). Specifically, when supervisors prioritize safety goals and provides adequate information, resources and support to deal with safety issues of workers, a perception of obligations for workers is expected to be generated to behave in a safer manner and promote organizational safety performance. By contrast, poor supervisorworker's relationship (e.g., supervisors present ambiguous safety goal priorities) will tend to weaken the workers' obligations to the onsite safety, and increase their tendency of breaking safety rules (Novak et al., 2017). Considering that construction industry often suffers from the constant tension between production and safety (Elmoujaddidi \& Bachir, 2018), high quality supervisor-workers relationship should be necessary to influence workers' decisions about whether to break safety rules or not.

Precious studies have revealed that LMX has a positive effect on workers' safety-related behaviours (Pan \& Lin, 2018). For instance, Lu et al. (2017) and Jiang, F. Li, Y. J. Li, and R. Li (2017) found that LMX was positively associated with employees' safety citizenship behaviours. Michael et al. (2006) suggested that organizations should foster positive social exchange between their workers and supervisors and enhance the qualities of LMX to reduce workers' violations and workplace injuries. Although previous studies have confirmed the positive effects of high-quality supervisor-worker relationship on the safety outcomes, they are mainly conducted in the general industries, and the implications of the supervisor-worker relationship remain relatively unexplored in construction industry (Chih et al., 2017). However, different from the general industries like the manufacture, construction industry suffers more from complex and dynamic working environment, constantly changing workforce, decentralized workplace, and workers' low project identity (Choi, Ahn, \& Lee, 2017b; Wu et al., 2018). These unique characteristics make frontline supervisor-worker relationship much more important for improving safety performance onsite. Accordingly, this research will explore the impact of LMX on safety violations specifically for the construction industry. This research argues that a high quality LMX relationship, can provide a platform for ensuring that workers develop positive attitudes towards safety, and eventually reduce workers' safety violations within the construction crew.

\subsection{Modified theory of planned behaviour}

Decision-making for specific behaviours are influenced by psychological issues, and one of the most reasonable theories has been suggested for demonstrating human behaviour is the theory of planned behaviour (TPB) (Javadi, Kadkhodaee, Yaghoubi, Maroufi, \& Shams, 2013; Maichum, Parichatnon, \& Peng, 2016). TPB, an extension of the theory of reasoned action (TRA), is a rational decision-making theory in dealing with behaviours in question (Conner, Smith, \& McMillan, 2003). According to TPB, human behaviour can be predicted from three sets of factors, including attitudes, subjective norms and perceived behaviour control (Yaskova \& Zaitseva, 2017). Attitudes refer to favourable or unfavourable evaluation of specific behaviours. Subjective norms come from the perception of the expectations of relevant others (e.g., leaders or co-workers). Perceived behaviour control involves individuals' confidence that they can perform the behaviours under investigation. As such, safety-specific framework of TPB mainly focuses on the prediction towards safety behaviours (Kim, Reicks, \& Sjoberg, 2003; Yuan, Wu, \& Zuo, 2018). TPB has been applied in various research fields to predict safety-related behaviour such as transportation (Jovanović, Šraml, Matović, \& Mićić, 2017), maintenance (Fogarty \& Shaw, 2010), and healthcare (Lapkin, Levett-Jones, \& Gilligan, 2015). Safety behaviours can be understood as the result of the socio-cognitive mediation process described by the TPB. The more favourable above three factors (i.e., attitudes) are towards engaging in safety behaviour, the more likely it is that workers will operate tasks safely (Lee, Yiu, \& Cheung, 2018).

Previous research has also employed TPB to promote safety behaviours in construction industry. For instance, Cavazza and Serpe (2010) explored the impact of safety training programs on unsafe behaviours through three TPB factors, namely attitudes towards behaviour, subjective norms, and perceived behavioural control. Goh and Sa'adon (2015) applied the TPB to explore the cognitive factors leading to the unsafe behaviours of not anchoring a safety harness when working at height onsite. Suo and Zhang (2017) developed a questionnaire based on TPB, and investigated the factors affecting the usage of safety footwear among Chinese migrating peasant construction workers. Although previous studies have confirmed that workers' safety violations could be explained through the framework of TPB, they are primarily limited in organiza- 
tional factors (e.g., safety training), or individual characteristics (Yang, Ubeynarayana, Wong, \& Guo, 2018), rare research focused on the influence of the supervisor-worker relationship quality at the crew level. More importantly, previous research primarily regarded safety attitude as a univalent concept (i.e., either positive or negative), which makes it ineffective to capture workers' psychological conflicts when committing safety violations (Cavazza \& Serpe, 2009). Therefore, the causal effect of on-site LMX on worker's behaviour based on a modified TPB framework where the safety attitude is replaced by attitudinal ambivalence is needed to be further explored and discussed.

\subsubsection{Attitudinal ambivalence toward safety compliance}

As mentioned above, attitudinal ambivalence toward safety compliance (AASC) refers to the extent to which an individual simultaneously holds both positive and negative attitudes toward safety compliance. Taking account of the prioritized production goal, workers normally tend to operate in an unsafe manner in the complex and dynamic construction site despite of the potential safety accidents or injuries. From this standpoint, AASC should be more accurate than traditional univalent attitude in capturing the psychological processes of committing safety violations. According to social information processing theory, work-related attitude could be shaped by interpreting the social information from immediate work environment (Salancik \& Pfeffer, 1978). As such, AASC can be influenced by social information, which may strengthen one side of conflicting psychology, and weaken another (Cavazza \& Serpe, 2009). LMX serves as a critical channel that transfers social information from supervisors to workers, and could be an interpersonal antecedent of AASC (Al-Atwi, 2016). In high-quality LMX, supervisors tend to prioritize safety goals, and convey workers consistently that safety is a core project value, which will weaken workers' attitudinal ambivalence (Novak et al., 2017). In contrast, a poor quality of LMX might increase workers' attitudinal ambivalence toward safety compliance since supervisors often present ambiguous safety goal priorities (Novak et al., 2017). Workers with high attitudinal ambivalence tend to give priority temporarily to production goal, and thus break safety rules (Xu et al., 2018). Accordingly, this research proposes that AASC will mediate the effect of LMX on individuals' safety violations. Meanwhile, workers with a lower AASC will have lower tendency to engage in either routine safety violations or situational safety violations (Mohamed, Ali, \& Tam, 2009). Based on these points of predicted direct and mediational effects, the following hypothesis is proposed:

H1a: LMX will have a negative correlation with AASC.

H1b: AASC will have a positive correlation with individuals' routine safety violations (IRSV).

H1c: AASC will have a positive correlation with individuals' situational safety violations (ISSV).
H1d: AASC will mediate the relationship between LMX and workers' IRSV.

H1e: AASC will mediate the relationship between LMX and workers' ISSV.

\subsubsection{Group safety norm}

Group safety norm (GSM) indicates social pressure to perform safety behaviour, namely, what others expect the individual should perform task safely (Rivis \& Sheeran, 2003). According to social cognition theory, individual workers always try to belong to a social group and adjust their own behaviours to what they believe is the socially acceptable within the crew (Roettger et al., 2017). When perceiving a positive group norm for safety behaviours (e.g., coworkers helps others' to achieve safety equipment when it is not available onsite), individuals will follow safety rules similarly to fit themselves with their groups (Liang, et al., 2018a, 2018b), and vice versa. Previous studies have confirmed that supervisors are critical for the formation of safety-related group norm within the construction crew. For instance, empirical study by Fang et al. (2015) of the Hong Kong construction industry, indicated that supervisors impact group-level safety climate, which in turn affects workers' safety behaviours. In addition, according to Zohar (2000), group safety climate which affects workers' safety violations in a group is based upon the relative value or importance the supervisor places on safety as perceived by the workers. From this standpoint, high quality relationship between supervisors and workers may contribute to a positive group safety norm within the crew, which will in turn reduce individuals' tendency to safety violations (Maichum et al., 2016). Based on these points of predicted direct and mediational effects, the following hypothesis is proposed:

H2a: LMX will have a positive correlation with group safety norm (GSM).

H2b: GSM will have a negative correlation with individuals' routine safety violations (IRSV).

$\mathrm{H} 2 \mathrm{c}$ : GSM will have a negative correlation with individuals' situational safety violations (ISSV).

H2d: GSM will mediate the relationship between LMX and workers' IRSV.

H2e: GSM will mediate the relationship between LMX and workers' ISSV.

\subsubsection{Perceived behavioural control}

Perceived behavioural control (PBC) is defined as the individuals' own perception of how easy or difficult it is to perform a particular behaviour (Mcmillan \& Conner, 2010). In other words, it measures the individuals' perceptions of the presence or absence of the requisite resources or opportunities for performing a specific behaviour (Mcmillan \& Conner, 2010). Previous research by Fugas, Silva, and Meliá (2012) had confirmed that organizational or supervisory factors are crucial to the formation of per- 
sonal control over safety onsite. Their research reported that supervisors' injunctive safety norms (i.e., one type of social influence, such as what ought to be done) had positive effects on workers' $\mathrm{PBC}$ regarding workplace safety (Fugas et al., 2012). In the dynamic construction environment, workers may feel that they are not able to complete work tasks by following safety procedures and rules because of external factors that are beyond their direct control (Maichum et al., 2016; Sheeran, Trafimow, Finlay, \& Norman, 2002). Lower perceived control will decrease the likelihood that workers' engagement of safety behaviours (Armitage \& Christian, 2003; Kohler, Cortina, Kurtessis, \& Golz, 2015). Therefore, if supervisors provide workers with the necessary resources and supports to deal with safety issues, namely, a high-quality relationship of LMX between supervisors and workers (Eisenberger, Stinglhamber, Vandenberghe, Sucharski, \& Rhoades, 2002), workers will feel higher confidence for improving workplace safety and operate safely correspondingly. Based on these points of predicted direct and mediational effects, the following hypotheses are proposed:

H3a: LMX will have a positive correlation with PBC.

$\mathrm{H} 3 \mathrm{~b}$ : PBC will have a negative correlation with RSV.

$\mathrm{H} 3 \mathrm{c}$ : PBC will have a negative correlation with SSV.

$\mathrm{H} 3 \mathrm{~d}$ : PBC will mediate the relationship between LMX and workers' IRSV.

H3e: PBC will mediate the relationship between LMX and workers' ISSV

This research aims to provide a better understanding of the mechanisms by which the LMX shapes the propensity of workers' safety violations on site. Specifically, this research develops an integrative model exploring the relationships among the quality of supervisor-member relationship (i.e., LMX), critical personal factors derived from modified TPB framework (i.e., attitudinal ambivalence toward safety compliance, group safety norm, and perceived behavioural control), and workers' safety-related behaviours (i.e., routine and situational safety violations), as illustrated by Figure 1. This model posits that the effects of LMX on individual workers' safety violations through the mechanism of TPB, namely that the intermediate variables mediate the relationship between LMX and workers' routine and situational safety violations.

\section{Methodologies}

\subsection{Measures}

\subsubsection{Leader-member exchange}

LMX describes exchange relationships between leaders and their subordinates (Schriesheim, Castro, \& Cogliser, 1999). The quality of information exchange between supervisors and workers on construction site was assessed by seven adapted items which were validated by the research of Janssen and Yperen (2004) and Graen and UhlBien (1995). These items featured the interactions between workers and their immediate supervisors regarding safety issues. Sample items include "My supervisor understands my safety problems and needs" and "My supervisor will use his or her power to help me solve safety problems".

\subsubsection{Attitudinal ambivalence, group safety norm and perceived behavioural control}

The modified TPB framework explained by attitudinal ambivalence toward safety compliance, group safety norm and perceived behavioural control, is applied to the prediction of violations. Attitudinal ambivalence toward safety compliance (AASC) refers to the extent to which an individual simultaneously holds both positive and negative attitudes toward safety compliance (Cacioppo et al., 1997). According to Cavazza and Serpe (2009), four items can be used to measure individuals' positive and negative safety attitude separately. There are two positive items, namely "Wearing personal protective equipment helps me avoid possible damage", and "Following safety procedures makes me feel safe". By contrast, two reverse items are also used including "Following safety procedures makes working more difficult", and "Wearing personal protective equipment bothers my daily work". Finally, an integrated ambivalence score was calculated using the formula suggested by Ran and Yamamoto (2015), the absolute difference between two components was subtracted from the

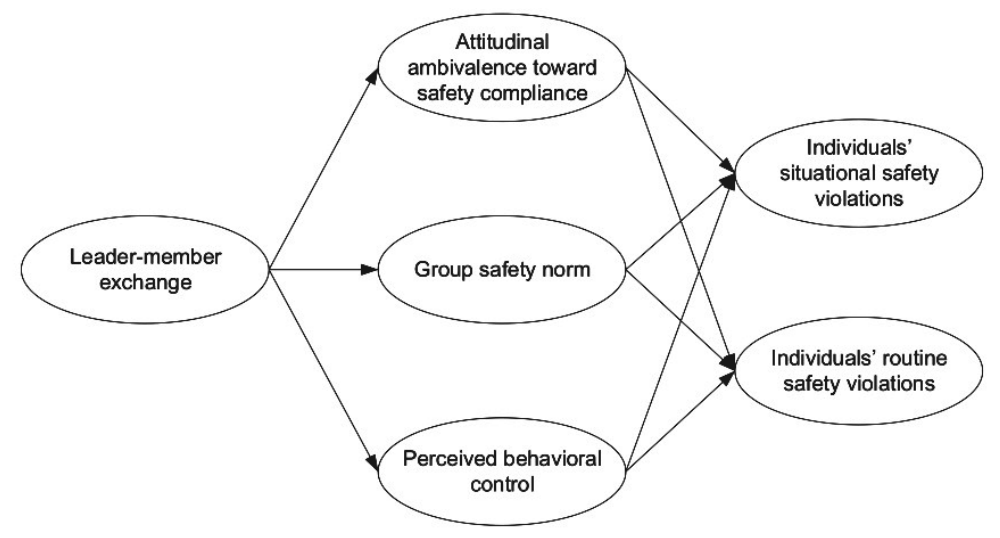

Figure 1. This hypothesized model in this research 
average, as shown in Eqn (1). $P$ denotes the total positive attitude score, and $N$ denotes the total negative attitude score. Higher scores indicate a higher level of ambivalence.

Attitudinal ambivalence toward safety compliance $=$

$$
\frac{(P+N)}{2}-P-N \text {. }
$$

Group safety norm (GSM) refers to the perception regarding whether significant others recognize the behaviour (Altmann \& Kroell, 2018). It was measured with another five items based on previous studies (Chan, Wong, Hon, Lyu, \& Javed, 2017; Fugas et al., 2012), which described the degree to which workmates attach importance to safety behaviours in crew. Sample items include "My workmates would react strongly against people who break safety procedures". "All the people who work in my crew are fully committed to safety procedures". "My workmates often discuss together about safety issues". A higher score indicated a higher group norm that an individual worker perceives within the crew.

The perceived behavioural control $(\mathrm{PBC})$ refers to a prejudgment of the possibility of performing certain behaviours, it was assessed with a two-item scale developed by Fugas et al. (2012), including "I feel I don't have control over the safety performance on my job". "For me, working safely is extremely difficult". The scores from the reverse items will be manually reversed before data analyses presented in the following section.

\subsubsection{Workers' safety violations}

The questions for assessing both routine and situational safety violations were adapted from the self-report items validated by Hansez and Chmiel (2010), Chmiel et al. (2017) and Laurent, Chmiel, and Hansez (2018). Routine safety violations were measured with four items, and a high score indicated a high level of violations. A sample item is "Occasionally I bend the rules when I know it is safe to do so". Situational safety violations were measured with six items and were reversely scored: a high score indicated a low level of violations. Sample items include "I always wear personal protective equipment, even when it's inconvenient and uncomfortable". "I always use safety equipment, even when it's not easily available".

\subsection{Participants and questionnaire administration}

Before the formal investigation, a pilot test was performed to ensure that question items were applicable for construction workers. A total of 19 workers participated in this pilot, based on which the initial questionnaire was revised. For instance, some questions were rephrased to make them much clearer for workers with a limited education. The final questionnaire consisted of two parts: general demographic questions including gender, age, years of work experience, education level, and trade type; and twenty-six safety-specific questions evaluated on a five-point Likert scale ranging from 1 (strongly disagree) to 5 (strongly agree). Safety-specific questions were developed to collect meaningful data that could capture the mediating effect of the factors hypothesized in Figure 1. Data were collected from construction-site workers in two large high-rise residential building projects located in Harbin and Shenyang. The questionnaires were distributed in person to a total of 300 construction workers. Participation was voluntary and the workers were not required to provide any personal or identifiable information in the questionnaire. Senior management from both projects provided necessary supports to facilitate this questionnaire such as emphasizing the pure academic purpose to their supervisors. Meanwhile, monetary compensation was provided to respondents who could answer all questions carefully. Workers who could not fully understand the questionnaire completed it with the help of the researchers to ensure the data quality. Finally, a total of 229 valid responses were used in the data analysis (a response rate of 76.3\%) after removing incomplete responses.

According to the statistical analysis among valid respondents, respondents were mostly male (97.4\%) due to the male-dominant workforce in the Chinese construction industry. Other demographic information was shown in Figure 2. Specifically, among the respondents, those belonging to the age groups of 30-39 and 40-49 accounted for the largest proportion of $35.8 \%$ and $36.2 \%$. A total of $14.4 \%$ of respondents had less than 5 years of work experience in construction, 66\% had 6-15 years of experience, and $19.6 \%$ had more than 16 years of work experience in construction, which indicates that they are very familiar with the workflow and operating environment. The majority of respondents (69\%) had completed primary or junior high school as their highest education, indicating that the level of education received by Chinese construction workers is still far from ideal (Liang et al., 2018a). Respondents were primarily from eight trade types: general (9.2\%), steel $(7 \%)$, scaffolding $(5.7 \%)$, concrete $(5.2 \%)$, carpenter $(28.8 \%)$, plasterer $(9.2 \%)$, bricklayer $(10 \%)$, welding $(8.7 \%)$, and others $(16.2 \%)$.

\subsection{Statistical procedures}

Based on the collected data, the hypotheses regarding the underlying mechanism through which LMX influences workers' safety violations, were tested using the structural equation modelling (SEM) procedures. SEM is a comprehensive statistical method to test hypotheses about relations among observed and latent variables (Newaz, Davis, Jefferies, \& Pillay, 2019). The computer program AMOS v21.0 and SPSS v18.0 (IBM, Armonk, New York, USA) were employed to perform statistical analysis and evaluate the overall fit of the model. Two-stage SEM approach was carried out to verify the measurement and structural models (Liang et al., 2018a). First, confirmatory factor analysis (CFA) was conducted to verify the reliability and validity of the measurement model. Next, path analysis is used to test the hypotheses of the structural model, especially the relationships among different latent variables. Since there is no consensus concerning the best index for assessing the overall fitness of SEM models 


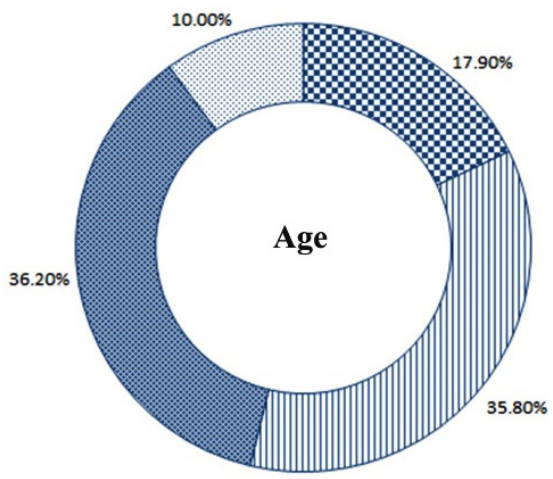

DAge 20-29 एAage 30-39 ॠAge 40-49 ఐAge 250

(a)

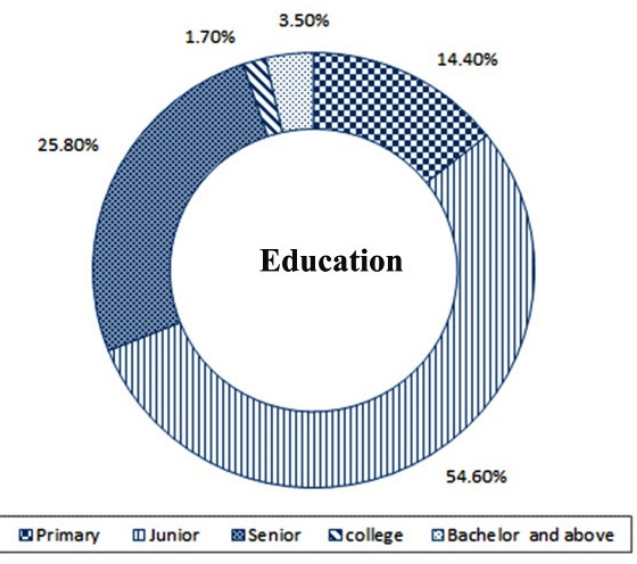

(c)

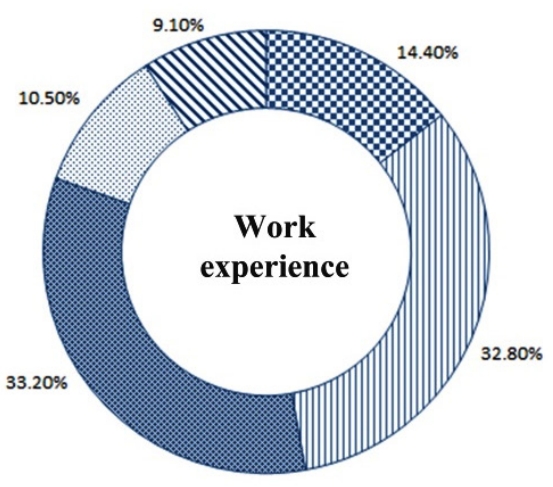

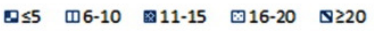

(b)

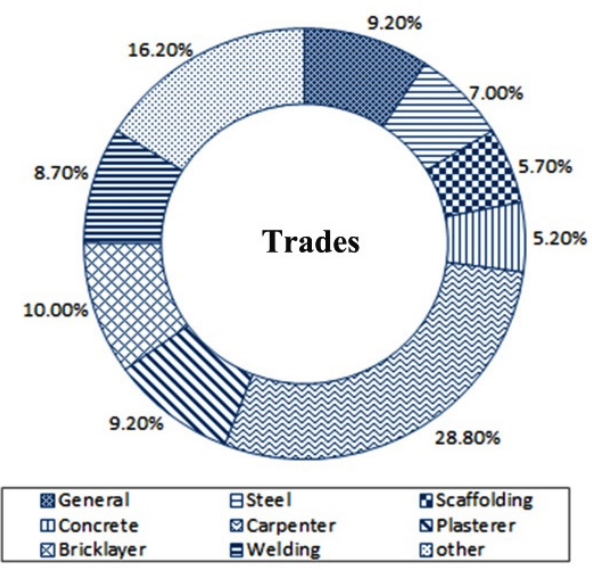

(d)

Figure 2. Statistics analysis in terms of (a) age; (b) work experience; (c) education; (d) trades

(Guo, Yiu, \& Gonzalez, 2016), multiple indexes were used to assess the model fit like previous research (Liang et al., 2018a). These indexes included the ratio of model chi-square to the degrees of freedom $\left(\chi^{2} / d f\right)$, the Root Mean Square Error of Approximation (RMSEA), the Incremental Fit Index (IFI), the Tucker-Lewis index (TLI), and the Comparative Fit index (CFI). To obtain acceptable model fit, Chi-square/ df should be between 1 and 3, CFI, TLI and IFI should be greater than 0.90, RMSEA should be less than 0.08 (Newaz et al., 2019; Shen, Ju, Koh, Rowlinson, \& Bridge, 2017).

\section{Results}

\subsection{Measurement model assessment}

The measurement model assessment aims to verify the construct reliability and validity through the confirmation factor analysis (CFA). During the CFA process, to adapt to the software environment, some abbreviations were used to represent eight constructs (shown in Table 1). The items with low factor loading values were deleted to ensure the validity of the measurement according to the suggestion made by $\mathrm{Wu}$ (2010). The final measurement model with acceptable goodness-of-fit is shown in Figure $3\left(\chi^{2} / d f=1.720\right.$; CFI = 0.965; $\mathrm{TLI}=0.953$; IFI $=0.965$; RMSEA $=0.056$ ). All FL values of measurement items were statistically significant at the 0.001 level. Table 2 shows the values of Cronbach's $\alpha$, composite reliability (CR), and average variance extracted (AVE) which were used to assess the construct reliability and convergent validity. The Cronbach's a values were all greater than recommended level of 0.70 (Cronbach, 1951), which confirms strong internal consistency reliability of the constructs. The AVEs and CRs of all constructs satisfied the threshold values of AVE of 0.5 (Wu, 2010) and CR of 0.70 (Hair, Anderson, Tatham, \& Black, 1998), respectively, supported the adequate construct convergence. The discriminant validity of all constructs was verified because the square roots of AVEs of any

Table 1. Glossary of abbreviations

\begin{tabular}{|c|l|}
\hline Abbreviations & \multicolumn{1}{|c|}{ Constructs } \\
\hline LMX & Leader-member-exchange \\
\hline AASC & $\begin{array}{l}\text { Attitudinal ambivalence towards safety } \\
\text { compliance }\end{array}$ \\
\hline GSM & Group safety norm \\
\hline PBC & Perceived behavioural control \\
\hline ISSV & Individuals' situational safety violations \\
\hline IRSV & Individuals' routine safety violations \\
\hline
\end{tabular}


Table 2. Descriptive statistics, construct reliability, and convergent validity

\begin{tabular}{|c|c|c|c|c|c|}
\hline Constructs & M & SD & Cronbach's $\alpha$ & CR & AVE \\
\hline LMX & 4.059 & 0.653 & 0.882 & 0.697 & 0.569 \\
AASC & 2.664 & 3.091 & - & - & - \\
GSM & 4.122 & 0.692 & 0.833 & 0.758 & 0.636 \\
PBC & 3.252 & 0.681 & 0.786 & 0.770 & 0.651 \\
IRSV & 2.402 & 0.958 & 0.839 & 0.749 & 0.626 \\
ISSV & 1.751 & 0.711 & 0.896 & 0.763 & 0.643 \\
\hline
\end{tabular}

(1) Abbreviations: $\mathrm{M}=$ Mean; $\mathrm{SD}=$ Standard deviation; $\mathrm{CR}=$ Composite reliability; AVE = Average variance extracted.

(2) Note: AASC is a one-indicator construct for which Cronbach's Alpha, CR, and AVE were not assessed here.

Table 3. The results of discriminant validity

\begin{tabular}{|c|c|c|c|c|c|c|c|}
\hline NO. & Constructs & 1 & 2 & 3 & 4 & 5 & 6 \\
\hline 1. & LMX & 0.754 & & & & & \\
2. & AASC & $-0.351^{* * *}$ & - & & & \\
3. & GSM & $0.642^{* * *}$ & $-0.374^{* * *}$ & 0.797 & & \\
4. & PBC & $0.221^{* * *}$ & $-0.453^{* * *}$ & 0.149 & 0.807 & & \\
5. & IRSV & $-0.510^{* * *}$ & $0.621^{\star * *}$ & $-0.423^{* * *}$ & $-0.640^{* * *}$ & 0.791 & \\
6. & ISSV & $-0.648^{\star * *}$ & $0.433^{* * *}$ & $-0.796^{* * *}$ & $-0.161^{\star * *}$ & $0.522^{* * *}$ & 0.802 \\
\hline
\end{tabular}

(1) Correlations are below the diagonal, and the figures in bold on the diagonal are the square root of the average variance extracted (AVE) of associated constructs. (2) ${ }^{* * *}=$ Correlation is significant at the 0.001 level.

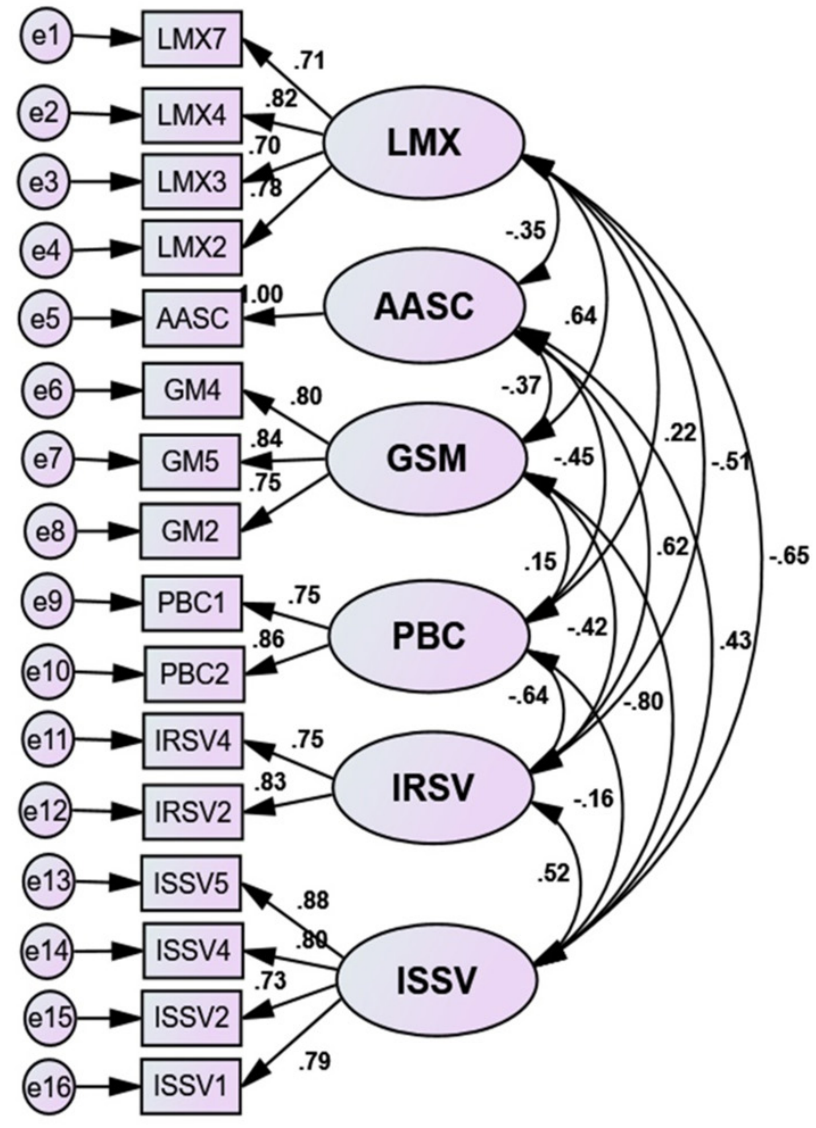

Figure 3. Final measurement model generated by AMOS v21 $\left(\chi^{2} / d f=1.720 ;\right.$ CFI $=0.965 ;$ TLI $=0.953 ;$ IFI $=0.965$; RMSEA $=0.056)$
As shown in Table 3, most constructs were significantly correlated $(\mathrm{p}<0.001)$. None of the correlation values exceeded the threshold value of 0.90 , suggesting the absence of multicollinearity (Hair et al., 1998).

\subsection{Structural model assessment}

After establishing the measurement model, the structural model assessment was performed. Figure 4 presents the estimated structural model and standardized path coefficients. The values of fit indices $\left(\chi^{2} / d f=2.202\right.$; CFI $=0.938$; TLI $=$ 0.922 ; IFI $=0.938$; RMSEA $=0.073$ ) were all within the recommended limits, suggesting that the hypothesized model could adequately fit the empirical data.

The corresponding hypothesis can be verified if the standardized path coefficient in the estimated structural model is significant and in the hypothesized direction (Shen et al., 2017). Specifically, hypotheses H1a, H2a and $\mathrm{H} 3 \mathrm{a}$ proposed that LMX would have a negative correlation with AASC, and positive correlations with GSM and $\mathrm{PBC}$, respectively. These three hypotheses were supported, and the results suggested LMX had a stronger effect on GSM (standardized path coefficient $\beta=0.69$; $p<$ $0.001)$ than AASC $(\beta=-0.39 ; \mathrm{p}<0.001)$ and PBC $(\beta=$ 0.26 ; $<<0.001)$. Hypotheses H1b and H1c proposed that AASC would have positive correlations with IRSV and ISSV. Both hypotheses were supported because two corresponding paths were statistically significant. Next, hypotheses $\mathrm{H} 2 \mathrm{~b}$ and $\mathrm{H} 2 \mathrm{c}$ were supported, and corresponding path coefficients suggested that the GSM has a stronger 


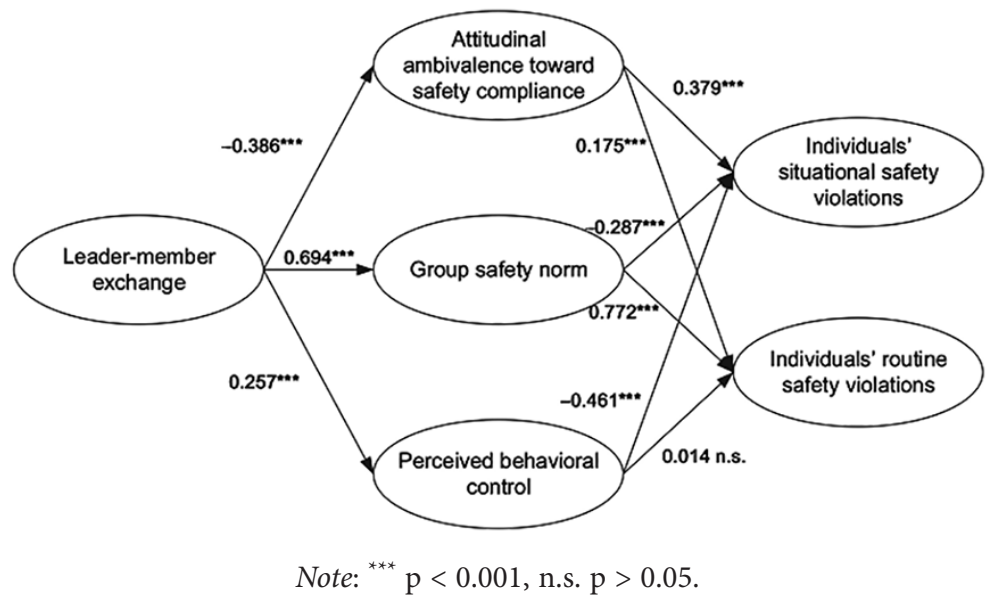

Figure 4 . The estimated structural model for total sample of workers $\left(\chi^{2} / d f=2.202\right.$; CFI $=0.938$; $\mathrm{TLI}=0.922 ; \mathrm{IFI}=0.938 ; \mathrm{RMSEA}=0.073$ )

effect on ISSV $(\beta=-0.77 ; \mathrm{p}<0.001)$ than IRSV $(\beta=-0.29$; $\mathrm{p}<0.001)$. H1d, H1e and H2d, H2e proposed that AASC and GSM would mediate the relationships between LMX and both types of individuals' safety violations. These hypotheses were supported since, in addition to both significant paths from LMX to AASC and GSM, four paths from AASC and GSM to both types of individuals' safety violations were also significant. However, hypothesis $\mathrm{H} 3$ could not be verified completely because the direct path from PBC to ISSV was not significant. Hence, PBC only had a significant effect on IRSV and only mediated the relationship between LMX and IRSV.

\section{Discussion}

The paper developed and tested a theoretical model to examine the mediating mechanisms between LMX and workers' safety violations based on the modified TPB theory. LMX represents mutual trust and commitment between supervisors and workers, which has been widely proven to be crucial to workplace safety improvement ( $\mathrm{Li}$ et al., 2018). However, there is still limited attentions to underlying mechanism through which LMX exerts the effects on workers' safety-related behaviours on the construction sites. This research proposed a modified TPB model where traditional univalent construct of safety attitudes was replaced by attitudinal ambivalence, which could better capture the workers' conflicting psychology towards safety violations onsite. As far as we know, this is the first research that attempts to explore the mediating mechanisms between LMX and workers safety violations (i.e., situational and routine safety violations) from a modified TPB perceptive. Therefore, this research could provide some meaningful insights into how to prevent safety violations in the construction industry. The following parts will discuss the main findings, limitations and future research in detail.

\subsection{The mediating mechanisms between LMX and safety violations}

\subsubsection{The mediating effect of AASC}

Through hypothesis $\mathrm{H} 1$, the research found that AASC mediated the negative association between LMX and workers' safety violations. This indicated that individuals in a high-quality relationship with their supervisors will have lower ambivalence towards safety compliance, which will further decrease the likelihood of performing safety violations. Construction workers tend to hold both positive and negative attitudes towards workplace safety (i.e., attitudinal ambivalence) given the conflicts between perceived costs and potential benefits from following safety rules (Cavazza \& Serpe, 2009). Therefore, in high-quality exchanges, individuals could receive more resources or emotional supports for working safely from their supervisors, which could weaken the cost side of the conflict (e.g., the supporting environment making safety compliance earlier), and enhance the benefits (e.g., potential monetary or social incentive), thereby reduce their attitudinal ambivalence. This is consistent with the previous research by Liang et al. (2018a, 2018b), which reported that perceived production pressure could increase the extent of individuals' attitudinal ambivalence, while perceived social support decreases attitudinal ambivalence. Furthermore, Individuals with higher attitudinal ambivalence are more likely to break safety rules because they suffer from more hesitations which hinder their decisions to work safely (Xu et al., 2018). The findings are consistent with the research put forward by Xu et al. (2018), which reported that attitudinal ambivalence have a higher direct effect on workers' unsafe behaviours than safety attitude (Xu et al., 2018). Similarly, Cavazza and Serpe (2009) found that attitudinal ambivalence towards usage of safety equipment mediates the effect of safety climate on safety violations. 


\subsubsection{The mediating effect of GSM}

Through hypotheses $\mathrm{H} 2$, the research found that GSM within the crew also mediates the effect LMX on individuals' safety violations. It indicates that supervisors could influence workers' safety behaviours through establishing a positive group norm regarding safety. Social exchange theory suggests that mutual trust and commitment between supervisors and workers (i.e., high LMX quality) will make workers obligated to reciprocate behaviours that benefit workplace safety (e.g., care about co-workers' safety within the crew), and thus facilitate the establishment of safety norm within the crew. The findings were in line with empirical research of Zohar (2002), which argued that leader-workers interactions had a positive correlation with workers' perception of safety norm within the workgroup. Furthermore, this research indicated that safety norm within the crew could have negative effects on both IRSV and ISSV. This finding could support the previous argument that workers' safety-related behaviours do not occur in a vacuum, but rather they are encouraged by the social context (Didla, Mearns, \& Flin, 2009; Friedkin \& Johnsen, 2011).

\subsubsection{The mediating effect of PBC}

Through hypotheses H3, the research suggested that LMX could exert negative effects on workers' safety violations through individuals' PBC. PBC reflects individuals' expectations regarding their capacity of performing safety behaviours onsite (Ajzen, 2002). Individuals in high-quality relationships with their supervisors could obtain requisite protective devices or technical guidance from their supervisors, which make them to feel more perceived control over safety onsite, such as lower conflicts between production and safety. Individuals with higher personal control tend to be more likely to perform task safely (Fugas et al., 2012). However, this research found that $P B C$ had a negative correlation with IRSV, while the effect on ISSV is not significant. This can be explained by that PBC herein was more about internal factors such as self-efficacy rather than external behavioural control such as facilitating condition or situational constraints (Ajzen, 1985). This finding suggests that IRSV involves more internal cognitive processes than the ISSV (Chmiel et al., 2017; Hansez \& Chmiel, 2010).

\subsection{The difference between situational and routine safety violations}

This research extends the scope of previous literature by considering the distinctions between different types of safety violations (situational and routine). As shown in Figure 4, three mediating variables have different effects on individuals' routine and situational violations. The GSM that describes a supportive environment has a stronger effect on ISSV $(\beta=-0.77 ; \mathrm{p}<0.001)$ than IRSV $(\beta=-0.29 ; p<0.001)$. This is consistent with previous finding by Chmiel et al. (2017), which argued that situational violations are more about the social-psychological processes, and could be predicted by workers' voluntary participation in safety activities. By contrast, attitudinal ambivalence and perceived behavioural control had more effects on routine safety violations. This findings provide further evidences that routine safety violations are shaped via cognitive-generical mechanisms (Chmiel et al., 2017), where individuals with higher ambivalent attitudes and lower perceived confidence towards safety were more likely perform short-cuts during the daily task implementation. These findings support and reinforce the notion that situational and routine safety violations are different types of violations with different mediators (Chmiel et al., 2017; Hansez \& Chmiel, 2010).

\subsection{Theoretical implications}

The findings of this research have theoretical implications for both leadership influence and occupational safety research. First, current construction safety research primarily focused on organizational or individual factors, while studies on the supervisors' leadership at the crew level, especially supervisor-worker relationship, were relatively rare. As far as we know, this is the first research which explored a conceptual model regarding the mediating mechanism underlying the relationship between LMX and individual's safety violations. Therefore, this research adds meaningful empirical insights from a social exchange perspective to the construction safety literature. Second, the results confirmed that individual's safety violations are shaped by supervisor-worker relationship quality within the crew (Fogarty \& Shaw, 2010). Furthermore, this research proposed a modified TPB framework by using attitudinal ambivalence as a novel mediating factor of safety violations. The findings gave the evidence that the attitudinal ambivalence plays critical mediating roles between LMX and safety violations. Compared with traditional univalent safety attitude, attitudinal ambivalence is more appropriate for understanding workers' psychological hesitation when committing safety violations. From this standpoint, this research may give new directions to apply this modified TPB to investigate safety violations not only for the construction workers, but also for employees in other high-risk industries. Third, our findings confirmed that situational and routine safety violations involve different leadership influential processes. Specifically, supervisor-worker relationship influences workers' routine safety violations mainly through attitudinal ambivalence and perceived behavioural control. By contrast, supervisor-worker relationship influences workers' situational safety violations mainly through group safety norm. This research extended previous literature which focused on workplace safety that treated safety violation as one single concept.

\subsection{Practical implications}

In addition to the theoretical implications, the findings in this research also have meaningful implications for organizational management practices. First, management should 
give importance to the crew-level measures, especially the supervisor-worker relationship for eliminating workers' safety violations onsite. Construction project should firstly raise awareness among supervisors about critical roles of supervisor-worker relationships. Then, training programs should be prepared specifically for frontline supervisors to enhance their leadership, communication skills and relationship management capacities, which enable them to establish mutual respect and trust with their workers (Chih et al., 2017). Second, the modified TPB model serves as a guideline for frontline supervisors to pay more attentions to reducing workers' attitudinal ambivalence, strengthening workers' perceived behavioural control and promoting group safety norm, through which supervisorworker relationship quality could eventually prevent safety violations onsite. Third, the findings indicated that the effects of supervisor-worker relationship on two types of safety violations (i.e., routine and situational) took place differently through above three mediating variables. Specially, for preventing routine safety violations, supervisors should be consistent to be "safety first" principle, instead of compromising safety under schedule or cost pressures, so as to reduce worker attitudinal ambivalence (Xu et al., 2018). Supervisors should also conduct safety training and communication, which ensure workers to be capable to balance conflicting work objectives (Liang et al., 2018a). For preventing situational violations, supervisors should create a supportive environment by demonstrating that they care about the safety issues to promote the formation of a great group norm, since the group norm is negatively related to workers' situational safety violations. The findings of this research will provide an important direction for optimizing management strategies and reducing the occurrence of different types of safety violations.

\subsection{Limitations and future research}

Despite the theoretical and practical contributions, as with any study, there are limitations to this one, many of which set the stage for additional research. First, the cross-sectional research design might limit the causal inferences on the relationships among LMX, three TPB variables and workers' safety violations. We argue that this problem should be minimal because the conceptual model is established based on reliable theories (e.g., social exchange theory and the TPB), and previous empirical research. Second, although participation was anonymous by nature, the self-reported data might have reduced the accuracy of safety violation measures considering the possibility of underreporting their safety violations. The third limitation of this study involves common method variance (CMV). A self-reported measure may raise the possibility that CMV may have spuriously produced the observed relationships. However, CMV is not a significant problem within our study considering the absence of multicollinearity. The CMV problem could be further verified by comparing a 1-factor (i.e., all items loaded on a common factor) model to the 6 -factor model. The confirmatory fac- tor analysis showed that the proposed 6-factor model provided a significantly better fit $\left(\chi^{2} / d f=1.720\right.$; CFI $=0.965$; $\mathrm{TLI}=0.953$; IFI $=0.965$; RMSEA $=0.056)$ than the 1 -factor model $\left(\chi^{2} / d f=6.608\right.$; $\mathrm{CFI}=0.685$; $\mathrm{TLI}=0.636$; $\mathrm{IFI}=$ 0.687; RMSEA $=0.157)$, meeting the criteria of the Harmon test (Podsakoff \& Organ, 1986). Thus, the influence of CMV should be minimal. Nonetheless, multisource data from supervisor- or coworker-reported and self-reported measures is recommended for future research. Forth, the proposed modified TPB model could better explain workers' conflicting psychology when committing safety violations, while this model did not add univalent safety attitude simultaneously in the interest of model parsimony. It could be supported empirical research of Xu et al. (2018), which found attitudinal ambivalence has much stronger direct effects on construction workers' safety violation intention than safety attitude does (Xu et al., 2018). In the future, an integrative TPB model that considers both safety attitude and attitudinal ambivalence is suggested to give further empirical evidences about the differences between safety attitude and attitudinal ambivalence in predicting safety violations. The fifth limitation is that the influences of national culture on construction workers' safety behaviour weren't taken into account, since different values and beliefs may exist in different nations and influenced workers' safety behaviours (Mearns \& Yule, 2009). In addition, we did not consider the role of individual's differences within the model. In future research, it's needed to further explore the moderating effects of individuals' differences (e.g. personal traits (Ilies, Scott, \& Judge, 2006)) to better understand the effect of safety violations among construction workers.

\section{Conclusions}

To the best of our knowledge, this research was the first to investigate the underlying mechanism of supervisor's impact on individual's safety violations through TPB. A theoretical model was established based on the questionnaire survey. The research has determined that individuals' safety violations are related to the social environment especially the interactions with their supervisors rather than a simply personal behaviour. The final model suggested that the quality of the relationship between supervisors and workers had an indirect effect on individuals' safety behaviours through the mediation mechanism of modified TPB including attitudinal ambivalence, group norm and perceived behavioural control. Furthermore, our findings confirmed the distinctions between situational and routine safety violations. According to the results, the influence of supervisors on situational safety violations was mainly mediated by group norm, while routine safety violations was mainly affected through the perceived behavioural control and attitudinal ambivalence. This paper provided practical insights into how to prevent the occurrence of different types of safety violations. The integrative model also formed a theoretical basis for safety management and strategies. 


\section{Acknowledgements}

The authors would like to show great appreciation to professor Nik Chmiel who generously shared the safety violation scales.

\section{Funding}

The work was supported by the Ministry of Science and Technology of the People's Republic of China under Grant No. 2016YFC0701606.

\section{Author contributions}

Huakang Liang were responsible for the development of conceptual model and questionnaire. Yikun $\mathrm{Su}$ and Huakang Liang were responsible for the data collection. Huakang Liang and Weiyi Cong were responsible for the paper writing. Weiyi Cong and Yikun Su made the same contributions.

\section{Disclosure statement}

No potential conflict of interest was reported by the authors.

\section{References}

Ajzen, I. (1985). From intentions to actions: A theory of planned behavior. Berlin Heidelberg: Springer.

https://doi.org/10.1007/978-3-642-69746-3_2

Ajzen, I. (1991). The theory of planned behavior. Organizational Behavior and Human Decision Processes, 50(2), 179-211. https://doi.org/10.1016/0749-5978(91)90020-T

Ajzen, I. (2002). Perceived behavioral control, self-efficacy, locus of control, and the theory of planned behavior. Journal of Applied Social Psychology, 32(4), 665-683. https://doi.org/10.1111/j.1559-1816.2002.tb00236.x

Al-Atwi, A. A. (2016). Personalized and depersonalized responses to leaders' fair treatment: Status judgments and leader-member exchange as mediating mechanisms. Group \& Organization Management, 43(6), 1037-1067. https://doi.org/10.1177/1059601116646471

Alper, S. J., \& Karsh, B.-T. (2009). A systematic review of safety violations in industry. Accident Analysis \& Prevention, 41(4), 739-754. https://doi.org/10.1016/j.aap.2009.03.013

Altmann, S., \& Kroell, C. (2018). Understanding employees' intention to take sabbaticals: Analyzing the role of supportive supervisors. Personnel Review, 47(4), 882-899. https://doi.org/10.1108/PR-01-2017-0021

Armitage, C. J., \& Christian, J. (2003). From attitudes to behaviour: Basic and applied research on the theory of planned behaviour. Current Psychology, 22(3), 187-195.

https://doi.org/10.1007/s12144-003-1015-5

Blackmon, G. M., \& Raghu, G. (1995). Pulmonary sarcoidosis: a mimic of respiratory infection. Seminars in Respiratory Infections, 10(3), 176-186.

Brandtmann, G., Scandura, M., \& Trillmich, F. (1999). Femalefemale conflict in the harem of a snail cichlid (Lamprologus ocellatus): Behavioural interactions and fitness consequences. Behaviour, 136, 1123-1144.

https://doi.org/10.1163/156853999501793
Cacioppo, J. T., Gardner, W. L., \& Berntson, G. G. (1997). Beyond bipolar conceptualizations and measures: the case of attitudes and evaluative space. Personality and Social Psychology Review, 1(1), 3-25. https://doi.org/10.1207/s15327957pspr0101_2

Cavazza, N., \& Serpe, A. (2009). Effects of safety climate on safety norm violations: exploring the mediating role of attitudinal ambivalence toward personal protective equipment. Journal of Safety Research, 40(4), 277-283. https://doi.org/10.1016/j.jsr.2009.06.002

Cavazza, N., \& Serpe, A. (2010). The impact of safety training programs on workers' psychosocial orientation and behaviour. Revue Internationale De Psychologie Sociale-International Review of Social Psychology, 23(2-3), 187-210.

Chan, A. P. C., Wong, F. K. W., Hon, C. K. H., Lyu, S., \& Javed, A. A. (2017). Investigating ethnic minorities' perceptions of safety climate in construction industry. Journal of Safety Research, 63, 9-19. https://doi.org/10.1016/j.jsr.2017.08.006

Chih, Y.-Y., Kiazad, K., Cheng, D., Lajom, J. A. L., \& Restubog, S. L. D. (2017). Feeling positive and productive: Role of supervisor-worker relationship in predicting construction workers' performance in the Philippines. Journal of Construction Engineering and Management, 143(8), 04017049. https://doi.org/10.1061/(ASCE)CO.1943-7862.0001346

Chmiel, N., Laurent, J., \& Hansez, I. (2017). Employee perspectives on safety citizenship behaviors and safety violations. Safety Science, 93, 96-107. https://doi.org/10.1016/j.ssci.2016.11.014

Choi, B., Ahn, S., \& Lee, S. (2017a). Construction workers' group norms and personal standards regarding safety behavior: social identity theory perspective. Journal of Management in Engineering, 33(4), 04017001.

https://doi.org/10.1061/(ASCE)ME.1943-5479.0000511

Choi, B., Ahn, S., \& Lee, S. (2017b). Role of social norms and social identifications in safety behavior of construction workers. I: Theoretical model of safety behavior under social influence. Journal of Construction Engineering and Management, 143(5), 04016124. https://doi.org/10.1061/(ASCE)CO.19437862.0001271

Conner, M., Smith, N., \& McMillan, B. (2003). Examining normative pressure in the theory of planned behaviour: Impact of gender and passengers on intentions to break the speed limit. Current Psychology, 22(3), 252-263. https://doi.org/10.1007/s12144-003-1020-8

Cronbach, L. J. (1951). Coefficient alpha and the internal structure of tests. Psychometrika, 16(3), 297-334. https://doi.org/10.1007/BF02310555

Cropanzano, R., \& Mitchell, M. S. (2005). Social exchange theory: An interdisciplinary review. Journal of Management, 31(6), 874-900. https://doi.org/10.1177/0149206305279602

Detert, J. R., \& Burris, E. R. (2007). Leadership behavior and employee voice: Is the door really open? Academy of Management Journal, 50(4), 869-884. https://doi.org/10.5465/amj.2007.26279183

Didla, S., Mearns, K., \& Flin, R. (2009). Safety citizenship behaviour: a proactive approach to risk management. Journal of Risk Research, 12(3-4), 475-483. https://doi.org/10.1080/13669870903041433

Eisenberger, R., Stinglhamber, F., Vandenberghe, C., Sucharski, I. L., \& Rhoades, L. (2002). Perceived supervisor support: Contributions to perceived organizational support and employee retention. Journal of Applied Psychology, 87(3), 565573. https://doi.org/10.1037/0021-9010.87.3.565 
Elmoujaddidi, F. P. S., \& Bachir, A. P. (2018). Perceived risk, safety climate and safety behaviour in Moroccan construction sites. International Journal of Occupational Safety and Ergonomics, 1-8. https://doi.org/10.1080/10803548.2018.1546461

Erdogan, B., Bauer, T. N., \& Taylor, S. (2015). Management commitment to the ecological environment and employees: Implications for employee attitudes and citizenship behaviors. Human Relations, 68(11), 1669-1691. https://doi.org/10.1177/0018726714565723

Fang, D., \& Wu, H. (2013). Development of a safety culture interaction (SCI) model for construction projects. Safety Science, 57, 138-149. https://doi.org/10.1016/j.ssci.2013.02.003

Fang, D., Wu, C., \& Wu, H. (2015). Impact of the supervisor on worker safety behavior in construction projects. Journal of Management in Engineering, 31(6), 04015001. https://doi.org/10.1061/(ASCE)ME.1943-5479.0000355

Fogarty, G. (2002). Explaining safety violations and errors in the construction industry. Australian Journal of Psychology, 54, 26-26.

Fogarty, G. J., \& Shaw, A. (2010). Safety climate and the theory of planned behavior: towards the prediction of unsafe behavior. Accident Analysis \& Prevention, 42(5), 1455-1459. https://doi.org/10.1016/j.aap.2009.08.008

Fornell, C., \& Larcker, D. F. (1981). Evaluating structural equation models with unobservable variables and measurement error. Journal of Marketing Research, 18(3), 375-381. https://doi.org/10.1177/002224378101800313

Friedkin, N. E., \& Johnsen, N. E. (2011). Social influence network theory: A sociological examination of small group dynamics. Cambridge: Cambridge University Press. https://doi.org/10.1017/CBO9780511976735

Fugas, C. S., Silva, S. A., \& Meliá, J. L. (2012). Another look at safety climate and safety behavior: Deepening the cognitive and social mediator mechanisms. Accident Analysis \& Prevention, 45, 468-477. https://doi.org/10.1016/j.aap.2011.08.013

Goh, Y. M., \& Saadon, N. F. B. (2015). Cognitive factors influencing safety behavior at height: A multimethod exploratory study. Journal of Construction Engineering and Management, 141(6), 04015003. https://doi.org/10.1061/(ASCE)CO.1943-7862.0000972

Golden, T. D., \& Veiga, J. F. (2018). Self-estrangement's toll on job performance: The pivotal role of social exchange relationships with coworkers. Journal of Management, 44(4), 15731597. https://doi.org/10.1177/0149206315615400

Graen, G. B., \& Uhl-Bien, M. (1995). Relationship-based approach to leadership: Development of leader-member exchange (LMX) theory of leadership over 25 years: Applying a multi-level multi-domain perspective. Leadership Quarterly, 6(2), 219-247. https://doi.org/10.1016/1048-9843(95)90036-5

Guo, B. H. W., Yiu, T. W., \& Gonzalez, V. A. (2016). Predicting safety behavior in the construction industry: Development and test of an integrative model. Safety Science, 84, 1-11. https://doi.org/10.1016/j.ssci.2015.11.020

Hair, J. F., Anderson, R. E., Tatham, R. L., \& Black, W. C. (1998). Multivariate data analysis ( $5^{\text {th }} \mathrm{ed}$.). New Jersey: Prentice Hall.

Halbesleben, J. R. B., Wakefield, D. S., \& Wakefield, B. J. (2008). Work-arounds in health care settings: Literature review and research agenda. Health Care Management Review, 33(1), 2-12. https://doi.org/10.1097/01.HMR.0000304495.95522.ca

Hansez, I., \& Chmiel, N. (2010). Safety behavior: Job demands, job resources, and perceived management commitment to safety. Journal of Occupational Health Psychology, 15(3), 267278. https://doi.org/10.1037/a0019528
Hardison, D., Behm, M., Hallowell, M. R., \& Fonooni, H. (2014). Identifying construction supervisor competencies for effective site safety. Safety Science, 65, 45-53. https://doi.org/10.1016/j.ssci.2013.12.013

Hofmann, D. A., Morgeson, F. P., \& Gerras, S. J. (2003). Climate as a moderator of the relationship between leader-member exchange and content specific citizenship: Safety climate as an exemplar. Journal of Applied Psychology, 88(1), 170-178. https://doi.org/10.1037/0021-9010.88.1.170

Ilies, R., Scott, B. A., \& Judge, T. A. (2006). The interactive effects of personal traits and experienced states on intraindividual patterns of citizenship behavior. Academy of Management Journal, 49(3), 561-575.

https://doi.org/10.5465/amj.2006.21794672

Janssen, O., \& Yperen, N. W. V. (2004). Employees' goal orientations, the quality of leader-member exchange, and the outcomes of job performance and job satisfaction. Academy of Management Journal, 47(3), 368-384. https://doi.org/10.5465/20159587

Javadi, M., Kadkhodaee, M., Yaghoubi, M., Maroufi, M., \& Shams, A. (2013). Applying theory of planned behavior in predicting of patient safety behaviors of nurses. Materia Socio-Medica, 25(1), 52-55. https://doi.org/10.5455/msm.2013.25.52-55

Jiang, L., Li, F., Li, Y. J., \& Li, R. (2017). Leader-member exchange and safety citizenship behavior: The mediating role of coworker trust. Work, 56(3), 387-395. https://doi.org/10.3233/WOR-172504

Jiang, Z., Fang, D., \& Zhang, M. (2015). Understanding the causation of construction workers' unsafe behaviors based on system dynamics modeling. Journal of Management in Engineering, 31(6), 04014099.

https://doi.org/10.1061/(ASCE)ME.1943-5479.0000350

Jovanović, D., Šraml, M., Matović, B., \& Mićić, S. (2017). An examination of the construct and predictive validity of the self-reported speeding behavior model. Accident Analysis \& Prevention, 99(Pt A), 66-76.

https://doi.org/10.1016/j.aap.2016.11.015

Kapp, E. A. (2012). The influence of supervisor leadership practices and perceived group safety climate on employee safety performance. Safety Science, 50(4), 1119-1124. https://doi.org/10.1016/j.ssci.2011.11.011

Kim, K., Reicks, M., \& Sjoberg, S. (2003). Applying the theory of planned behavior to predict dairy product consumption by older adults. Journal of Nutrition Education \& Behavior, 35(6), 294-301. https://doi.org/10.1016/S1499-4046(06)60343-6

Kohler, T., Cortina, J. M., Kurtessis, J. N., \& Golz, M. (2015). Are we correcting correctly?: Interdependence of reliabilities in meta-analysis. Organizational Research Methods, 18(3), 355428. https://doi.org/10.1177/1094428114563617

Lapkin, S., Levett-Jones, T., \& Gilligan, C. (2015). Using the theory of planned behaviour to examine health professional students' behavioural intentions in relation to medication safety and collaborative practice. Nurse Education Today, 35(8), 935940. https://doi.org/10.1016/j.nedt.2015.03.018

Laurent, J., Chmiel, N., \& Hansez, I. (2018). Jobs and safety: A social exchange perspective in explaining safety citizenship behaviors and safety violations. Safety Science, 110, 291-299. https://doi.org/10.1016/j.ssci.2018.08.027

Lee, C. K., Yiu, T. W., \& Cheung, S. O. (2018). Application of the theory of planned behavior to alternative dispute resolution selection and use in construction projects. Journal of Legal Affairs and Dispute Resolution in Engineering and Construction, 10(2), 04518003.

https://doi.org/10.1061/(ASCE)LA.1943-4170.0000252 
Li, S., Fan, M., \& Wu, X. (2018). Effect of social capital between construction supervisors and workers on workers' safety behavior. Journal of Construction Engineering and Management, 144(4), 04018014.

https://doi.org/10.1061/(ASCE)CO.1943-7862.0001467

Liang, H., Lin, K.-Y., Zhang, S., \& Su, Y. (2018a). The impact of coworkers' safety violations on an individual worker: A social contagion effect within the construction crew. International Journal of Environmental Research and Public Health, 15(4), 773. https://doi.org/10.3390/ijerph15040773

Liang, H., Zhang, S., \& Su, Y. (2018b). The structure and emerging trends of construction safety management research: a bibliometric review. International Journal of Occupational Safety and Ergonomics, 1-20. https://doi.org/10.1080/10803548.2018.1444565

Lingard, H., Cooke, T., \& Blismas, N. (2011). Coworkers' response to occupational health and safety: An overlooked dimension of group-level safety climate in the construction industry? Engineering, Construction and Architectural Management, 18(2), 159-175. https://doi.org/10.1108/09699981111111139

Lingard, H., Cooke, T., \& Blismas, N. (2012). Do perceptions of supervisors' safety responses mediate the relationship between perceptions of the organizational safety climate and incident rates in the construction supply chain? Journal of Construction Engineering and Management, 138(2), 234-241. https://doi.org/10.1061/(ASCE)CO.1943-7862.0000372

Lu, C. S., Weng, H. K., \& Lee, C. W. (2017). Leader-member exchange, safety climate and employees' safety organizational citizenship behaviors in container terminal operators. Maritime Business Review, 2(4), 331-348. https://doi.org/10.1108/MABR-11-2017-0028

Maichum, K., Parichatnon, S., \& Peng, K.-C. (2016). Application of the extended theory of planned behavior model to investigate purchase intention of green products among Thai consumers. Sustainability, 8(10), 1077.

https://doi.org/10.3390/su8101077

Man, S. S., Chan, A. H. S., \& Wong, H. M. (2017). Risk-taking behaviors of Hong Kong construction workers - A thematic study. Safety Science, 98, 25-36. https://doi.org/10.1016/j.ssci.2017.05.004

Mariani, M. G., Curcuruto, M., Matic, M., Sciacovelli, P., \& Toderi, S. (2017). Can leader-member exchange contribute to safety performance in an Italian warehouse? Frontiers in Psychology, 8, 9. https://doi.org/10.3389/fpsyg.2017.00729

Mcmillan, B., \& Conner, M. (2010). Applying an extended version of the theory of planned behavior to illicit drug use among students. Journal of Applied Social Psychology, 33(8), 1662-1683. https://doi.org/10.1111/j.1559-1816.2003.tb01968.x

Mearns, K., \& Yule, S. (2009). The role of national culture in determining safety performance: Challenges for the global oil and gas industry. Safety Science, 47(6), 777-785. https://doi.org/10.1016/j.ssci.2008.01.009

Michael, J. H., Guo, Z. G., Wiedenbeck, J. K., \& Ray, C. D. (2006). Production supervisor impacts on subordinates' safety outcomes: An investigation of leader-member exchange and safety communication. Journal of Safety Research, 37(5), 469-477. https://doi.org/10.1016/j.jsr.2006.06.004

Mohamed, S., Ali, T. H., \& Tam, W. Y. V. (2009). National culture and safe work behaviour of construction workers in Pakistan. Safety Science, 47(1), 29-35.

https://doi.org/10.1016/j.ssci.2008.01.003
Nahrgang, J. D., Morgeson, F. P., \& Ilies, R. (2009). The development of leader-member exchanges: Exploring how personality and performance influence leader and member relationships over time. Organizational Behavior and Human Decision Processes, 108(2), 256-266.

https://doi.org/10.1016/j.obhdp.2008.09.002

Newaz, M. T., Davis, P., Jefferies, M., \& Pillay, M. (2019). The psychological contract: A missing link between safety climate and safety behaviour on construction sites. Safety Science, 112, 9-17. https://doi.org/10.1016/j.ssci.2018.10.002

Novak, J., Farr-Wharton, B., Brunetto, Y., Shacklock, K., \& Brown, K. (2017). Safety outcomes for engineering asset management organizations: Old problem with new solutions? Reliability Engineering \& System Safety, 160, 67-73. https://doi.org/10.1016/j.ress.2016.12.004

Pan, S.-Y., \& Lin, K. J. (2018). Who suffers when supervisors are unhappy? The roles of leader-member exchange and abusive supervision. Journal of Business Ethics, 151(3), 799-811. https://doi.org/10.1007/s10551-016-3247-y

Phipps, D. L., Beatty, P. C., \& Parker, D. (2015). Standard deviation? The role of perceived behavioural control in procedural violations. Safety Science, 72, 66-74. https://doi.org/10.1016/j.ssci.2014.08.009

Podsakoff, P. M., \& Organ, D. W. (1986). Self-reports in organizational research: Problems and prospects. Journal of Management, 12(4), 531. https://doi.org/10.1177/014920638601200408

Ran, W., \& Yamamoto, M. (2015). Attitudinal ambivalence as a protective factor against junk food advertisements: A moderated mediation model of behavioral intention. Journal of Health Communication, 20(8), 893-902. https://doi.org/10.1080/10810730.2015.1018598

Rivis, A., \& Sheeran, P. (2003). Descriptive norms as an additional predictor in the theory of planned behaviour: A metaanalysis. Current Psychology, 22(3), 218-233. https://doi.org/10.1007/s12144-003-1018-2

Roettger, S., Maier, J., Krex-Brinkmann, L., Kowalski, J. T., Krick, A., Felfe, J., \& Stein, M. (2017). Social cognitive aspects of the participation in workplace health promotion as revealed by the theory of planned behavior. Preventive Medicine, 105, 104-108. https://doi.org/10.1016/j.ypmed.2017.09.004

Salancik, G. R., \& Pfeffer, J. (1978). A social information processing approach to job attitudes and task design. Administrative Science Quarterly, 224-253. https://doi.org/10.2307/2392563

Schriesheim, C. A., Castro, S. L., \& Cogliser, C. C. (1999). Leader-member exchange (LMX) research: A comprehensive review of theory, measurement, and data-analytic practices. Leadership Quarterly, 10(1), 63.

https://doi.org/10.1016/S1048-9843(99)80009-5

Sheeran, P., Trafimow, D., Finlay, K. A., \& Norman, P. (2002). Evidence that the type of person affects the strength of the perceived behavioural control-intention relationship. British Journal of Social Psychology, 41, 253-270. https://doi.org/10.1348/014466602760060129

Shen, Y., Ju, C., Koh, T. Y., Rowlinson, S., \& Bridge, A. J. (2017). The impact of transformational leadership on safety climate and individual safety behavior on construction sites. International Journal of Environmental Research and Public Health, 14(1). https://doi.org/10.3390/ijerph14010045

Shin, M., Lee, H.-S., Park, M., Moon, M., \& Han, S. (2014). A system dynamics approach for modeling construction workers' safety attitudes and behaviors. Accident Analysis \& Prevention, 68(Supplement C), 95-105. https://doi.org/10.1016/j.aap.2013.09.019 
Shore, L. M., \& Wayne, S. J. (1993). Commitment and employee behavior: comparison of affective commitment and continuance commitment with perceived organizational support. The Journal of Applied Psychology, 78(5), 774-780. https://doi.org/10.1037/0021-9010.78.5.774

Suo, Q. H., \& Zhang, D. M. (2017). Investigation and identification of factors affecting migrating peasant workers' usage of safety footwear in the Chinese construction industry. International Journal of Occupational Safety and Ergonomics, 23(3), 424-430. https://doi.org/10.1080/10803548.2016.1277081

Walumbwa, F. O., Cropanzano, R., \& Goldman, B. M. (2011). How leader-member exchange influences effective work behaviors: Social exchange and internal-external efficiency perspectives. Personnel Psychology, 64(3), 739-770. https://doi.org/10.1111/j.1744-6570.2011.01224.x

Wu, M. L. (2010). Structural equation model - The operation and application of Amos. Chongqing, China: Chongqing University Press.

Wu, X. Y., Chong, H. Y., Wang, G., \& Li, S. Q. (2018). The influence of social capitalism on construction safety behaviors: An exploratory megaproject case study. Sustainability, 10(9), 3098. https://doi.org/10.3390/su10093098

Xu, S., Zou, P. X., \& Luo, H. (2018). Impact of attitudinal ambivalence on safety behaviour in construction. Advances in Civil Engineering, Article ID 7138930. https://doi.org/10.1155/2018/7138930
Yang, M. G., Ubeynarayana, C. U., Wong, K. L. X., \& Guo, B. H. W. (2018). Factors influencing unsafe behaviors: A supervised learning approach. Accident Analysis \& Prevention, 118, 77-85. https://doi.org/10.1016/j.aap.2018.06.002

Yaskova, N., \& Zaitseva, L. (2017). Application of alternative dispute resolution in the field of construction projects. IOP Conference Series: Earth and Environmental Science, 90(1), 012182. https://doi.org/10.1088/1755-1315/90/1/012182

Yuan, H., Wu, H., \& Zuo, J. (2018). Understanding factors influencing project managers' behavioral intentions to reduce waste in construction projects. Journal of Management in Engineering, 34(6), 04018031. https://doi.org/10.1061/(ASCE)ME.1943-5479.0000642

Zhang, P. Y., Li, N., Fang, D. P., \& Wu, H. J. (2017). Supervisorfocused behavior-based safety method for the construction industry: Case study in Hong Kong. Journal of Construction Engineering and Management, 143(7), 05017009. https://doi.org/10.1061/(ASCE)CO.1943-7862.0001294

Zohar, D. (2000). A group-level model of safety climate: Testing the effect of group climate on microaccidents in manufacturing jobs. Journal of Applied Psychology, 85(4), 587-596. https://doi.org/10.1037/0021-9010.85.4.587

Zohar, D. (2002). The effects of leadership dimensions, safety climate, and assigned priorities on minor injuries in work groups. Journal of Organizational Behavior, 23(1), 75-92. https://doi.org/10.1002/job.130 